\title{
Integration of resilience and sustainability: from theory to application
}

\author{
Nebil Achour, Efthimia Pantzartzis, Federica Pascale and \\ Andrew D.F. Price \\ School of Civil and Building Engineering, Loughborough University, \\ Loughborough, UK
}

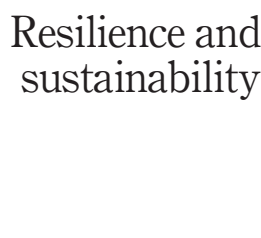

Received 7 May 2013 Revised 24 April 2014 23 May 2014

Accepted 27 May 2014

\begin{abstract}
Purpose - This study aims to explore the challenges associated with the integration of resilience and sustainability, and propose a workable solution that ensures resilient and sustainable buildings. Recent research outcomes suggest that the number of natural hazards, both environmental and geophysical, will increase due to the effect of global warming. Various approaches have been investigated to reduce environmental degradation and to improve the physical resilience to natural hazards. However, most of these approaches are fragmented and when combined with cultural barriers, they often result into less-efficient assessment tools.

Design/methodology/approach - The primary source of information used to develop this paper has been research publications, policy papers, reports and tool guidelines. A set of questions were developed to guide the review which was complemented with information distilled from the HFA 2005-2015 to develop an integration process to evaluate 10 international sustainability appraisal tools.

Findings - The major finding of this research is that, from a technical point of view, resilience and sustainability could be integrated. However, it requires a long and thorough process with a multidisciplinary stakeholder team including technical, strategic, social and political parties. A combination of incentives and policies would support this process and help people work towards the integration. The Japanese model demonstrates a successful case in engaging stakeholders in the process which led to the development of a comprehensive appraisal tool, CASBEE ${ }^{\circledR}$, where resilience and sustainability are integrated.

Practical implications - Although data have been sought through literature review (i.e. secondary data), the research is expected to have significant impact, as it provides a clear theoretical foundation and methods for those wishing to integrate resilience within current sustainability appraisal tools or develop new tools.

Social implications - This paper provides original concepts that are required to reduce fragmentation in the way resilience and sustainability are addressed. It sets up a new research agenda which has the potential to have a strong impact due the fact that sustainability and resilience are getting higher on the political priority scale.

Originality/value - This paper provides findings of an original idea to reduce fragmentation in the way resilience and sustainability are addressed. It sets up a new research agenda which has the

(C) Nebil Achour, Efthimia Pantzartzis, Federica Pascale and Andrew D.F. Price. Published by Emerald Group Publishing Limited. This article is published under the Creative Commons Attribution (CCBY 3.0) licence. Anyone may reproduce, distribute, translate and create derivative works of this article (for both commercial \& non-commercial purposes), subject to full attribution to the original publication and authors. The full terms of this licence may be seen at http:// creativecommons.org/licences/by/3.0/legalcode
\end{abstract}

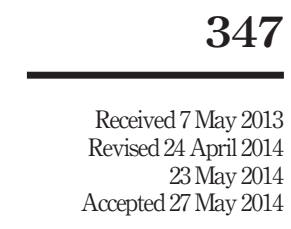

(2)

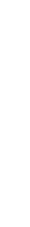


IJDRBE 6,3 potential to have a strong impact due the fact that sustainability and resilience are getting higher on the political priority scale.

Keywords Change, Integration, Disaster resilience, Natural hazards, Built environment infrastructure, Sustainability appraisal tool

Paper type Research paper

\section{Background}

Disasters "are not always singular or isolated events [...] they can occur in complex combinations and, or rapid succession" (EEA, 2003), as demonstrated by the experience of many countries, such as Japan in 2004 and 2011 and China in 2008. There have recently been several highly disruptive natural events demonstrating the complexity and diversity of impact associated with natural hazards. Recent research suggests that the number of natural hazards, both environmental and geo-physical, will increase due to the effect of global warming (Sauber and Ruppert, 2008; Hetzel and Hampel, 2006). Although the connection between geo-physical hazards and global warming is still under debate, there is an urgent need to design more resilient and sustainable buildings and infrastructures able to cope with natural hazards and sustainable enough to mitigate the impact on global warming and climate change. Researchers such as Mileti (1999), Achour (2007), Achour and Price (2010) and Moe (2012) have linked disaster risk reduction and sustainability; for example:

[...] community that wants to become more sustainable will: maintain and, if possible, enhance, its residents' quality of life; enhance local economic vitality; ensure social and intergenerational equity; maintain and, if possible, enhance, environmental quality; incorporate disaster resilience and mitigation; and use a consensus-building, participatory process when making decisions (Mileti, 1999) due to the close interrelationship between disaster reduction and sustainable development, which was already recognised at the United

Nations Conference on Environment and Development and taken into account in Agenda 21 (UN General Assembly, 1994).

However, in practice, individuals tend to treat these two important aspects separately, which could compromise environmental preservation and/or resilience.

\section{Aim and methodology}

The aim of this paper is to explore the challenges associated with the integration of resilience and sustainability, and propose a workable solution that ensures resilient and sustainable buildings. This is a first step and exploratory research work investigating the need for integrating resilience and sustainability as a way to ensure that buildings do meet the minimum requirements of both resilience and sustainability. The research adopted a qualitative method "concerned with developing explanations of social phenomena" (Hancock, 2002) to acquire "a holistic view of the phenomena under investigation" (Bogdan and Taylor, 1975; Patton, 1980 cited in Matveev, 2002) and "a more realistic feel of the world that cannot be experienced in the numerical data and statistical analysis used in quantitative research" (Matveev, 2002). The main sources of data are information published in key research and policy papers, reports and tool guidelines. The review dealt with finding answers to three major research questions:

$R Q 1$. What evidence is there in literature to support or contest the integration of resilience and sustainability? 
$R Q 2$. Which theories can be adapted to enhance the integration?

Resilience and

$R Q 3$. What is the process to convert theory into practice?

An exploratory literature review was conducted to explore how resilience and sustainability have been dealt with and to identify the challenges related to their integration. This involved the identification of theories dealing with sustainability with the view to create opportunities to integrate resilience and was complemented with information distilled from the Hyogo Framework for Action (HFA) 2005-2015 to support the integration process. Collected data were analysed following a Thematic Approach to identify the key factors able to drive change, and then linked according to an "action-reaction" model to develop an "integration process", involving the parties who could drive the integration. Findings were supplemented with an in-depth investigation of 10 international sustainability appraisal tools, covering most of the world's geographical areas, from Australia, Brazil, Canada, France, Germany, Honk Kong, Japan, Singapore, the UK and the USA, to evaluate the integration and identify where this could be addressed. The investigation involved scrutinising each tool's checkpoints to answer three major questions to identify the level of integration between the key change drivers (identified via the HFA). These questions are:

Q1. What are the assessment criteria of each tool?

Q2. How has resilience been integrated?

Q3. What model can be adopted to integrate resilience and sustainability?

\section{Resilience and sustainability: unbalanced attention}

The historical records of the UK suggest that the country is less exposed to major disasters, when compared to countries such as Japan, the USA and China, where natural hazards are more frequent and severer. Consequently, the UK's recent priorities have focused on sustainability more than resilience. Financial, legislative and even political resources were devoted: the former Prime Minister, Gordon Brown, established the Department of Energy and Climate Change (DECC) in October 2008, which has since been responsible for saving, delivering and managing energy more efficiently with emphasis on low carbon. Major refurbishments have been conducted to improve the sustainability of public and private, commercial and residential buildings' stock mainly through insulation, day lighting, heating and natural ventilation to meet with the targets set by the Climate Change Act 2008, "to cut emissions by 80 per cent of their 1990 levels by 2050 with a mid-term target of 34 per cent cut by 2020" (McGrath, 2009). Although the ability to meet these targets is still debatable, it demonstrates the emphasis and commitment to environmental protection. Since 2000, a series of extreme weather events have taken place, affecting hundreds of thousands of people across the country, thus resulting in increased concern for improved critical infrastructure resilience. However, the level of attention paid to resilience was not sufficient, as "large parts of the UK's infrastructure including energy and transport networks are vulnerable to bad weather" (BBC, 2009) and that:

[...] infrastructure investment was not considered a priority in the competition for government resources. Between 2000 and 2007, the UK was the lowest investor in infrastructure of all the OECD countries - with an estimated infrastructure deficit of $£ 500 \mathrm{bn}$ over the next decade (ARUP, 2011). 
IJDRBE

6,3

350
Figure 1.

Integrated resilience and sustainability model
UK infrastructure comprises many ageing vulnerable assets, some dating back to the Victorian era, such as the Dungeness power plant, which is built few meters above sea level on an "unstable geological formation" (Paskal, 2009), which could be a source of an "environmental disaster". The UK Government plans to update and upgrade much of its critical infrastructures. Within these plans, risks associated with earthquakes "would be dismissed as possibilities" and flood risks "will not stop" the plans (BBC, 2008), ignoring the fact that 2005, 2007 and 2014 floods caused the country billions of pounds. Therefore, despite efforts to improve resilience in the UK, there is risk of unbalanced attention between environmental preservation and resilience to disasters. However, recent reports and inadequate performance of infrastructure during recent extreme weather events drove authorities to conclude that there is a need to update and improve resilience of infrastructure (HM Treasury, 2013). It is timely to ensure that the future work will be "balanced" by following requirements of sustainability and resilience and to better understand social value and impact when the government makes its spending plans, which due to the recent recession focussed on economic value rather than quality. There is a clear need to integrate these issues more; however, there is a lack of clarity on how this integration could be achieved, which has led practitioners to deal with resilience and sustainability as two separate issues.

\section{Conceptual model to integrate resilience and sustainability}

There are many drivers for integrating resilience and sustainability; however, there is delay in doing so due to a lack of awareness and motivation among key decision makers and technical, financial, and legislative resources to guarantee that the minimum requirements are met. Conversely, there is significant amount of information and datasets available worldwide that can be used for the integration.

Sustainability is about assessing the potential impact, positive or negative, a project or an activity could have on environmental, social and economic issues, see Figure 1(a). This model was first developed in the USA in 1969 and later adopted in many countries

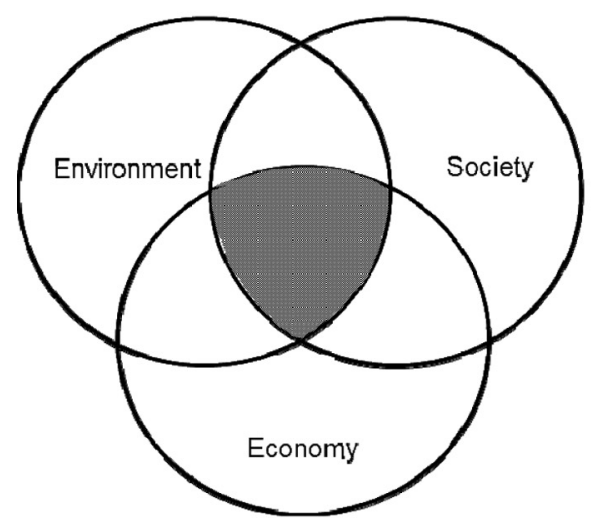

(a)

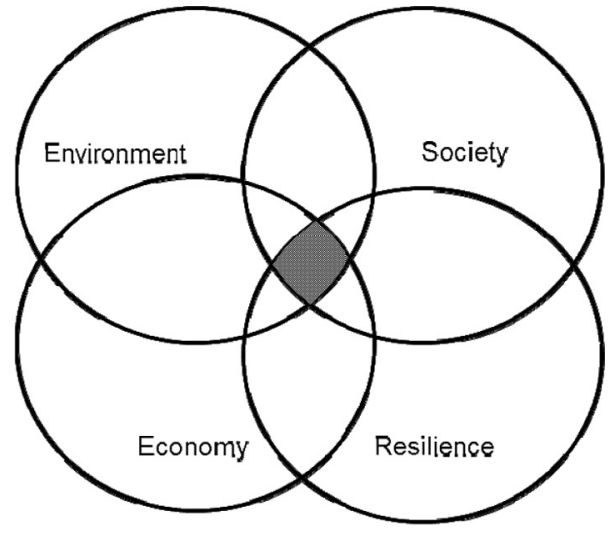

(b)
Notes: (a) Resilience and sustainability before integration; (b) resilience and sustainability after integration 
(IIED, 2009) such as the UK, where a number of strategies and targets have been set and enhanced with legislations, guidance and tools, and clarifies some of the reasons for which there is the "unbalanced" attention resilience and sustainability. Disasters are now firmly on the agenda of many countries specifically after the recent experience of the Japanese mega-earthquake of March 2011 in addition to the speed with which climate is changing, the potential risks and the high vulnerability of critical infrastructure and built environment in many countries. However, the fact that these two are still dealt with as two separate issues is a major concern, as it fails in meeting with the HFA2005-2015 recommendations for the integration and increases the chance of inefficient budget spending due to inappropriate and risky allocation. Project planning thus needs to be challenged further by adding the "resilience" element to the set of sustainability aspects (society, environment and economy). This combination will ensure that infrastructure must be environmentally, economically and socially viable and resilient enough to cope with disruptions [see Figure 1(b)].

\section{Resilience and sustainability integration process}

The World Conference on Disaster Reduction, held in Kobe in January 2005, set a clear strategy towards increasing awareness of the importance of national and community resilience to disasters. The outcome of this activity was the development of the HFA 2005-2015, where five priorities were identified and supported by a set of guidelines to consider while improving resilience, as shown in Table I. When re-arranged, according to "who can do what", the guidelines could be classified into four major elements: political (including legal), social, technical and strategic planning, which are related to each other with an "action-reaction" process as that shown in Figure 2. The change initiative could start from any particular side, technical, political or social, to inform the strategic planning which is required to develop the necessary strategies, targets and feedback to technical and political for execution and enforcement, and inform social about the emerging strategies. The process seems to be easy and straightforward; however, there are many barriers, some of which relate to technical capability, resources and psychology due to risk perception and prioritisation. Individuals, institutions and even governments tend to prioritise their need for better impact and also for availability of resources; this often results in neglecting less pressuring risks. For example, risk of death due to car accident is higher than that due to natural hazard (Arnold et al., 2004), which means that resources and focus will naturally be more on developing policies and improving infrastructure in a way that reduces the impact of traffic accidents rather than coping with natural hazards.

The integration is expected to add another layer of complexity to the way resilience and sustainability are addressed. It can be viewed as a change that involves different parties often with different agendas and priorities, and thus will rise up the level of challenges. Höög et al. (2013) highlighted that inter and intra groups/parties communication is an area that could be challenging due to perceptions and perspective solutions. This implies that there is a risk of people becoming less cooperative and perceiving change as an overwhelming effort (FHWA, 2013). The problem could be extended further if integration is viewed as a business case which will ultimately deviate from its intended direction. An example of this has been reported by Scrase and Sheate (2002), who stated that "Environmental Management Systems (EMS) are business based procedures" recognising that EMS reduced fragmentation and provided better evidence 


\section{IJDRBE \\ 6,3}

352

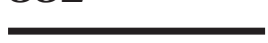

Table I.

Integration of resilience and environmental preservation in HFA

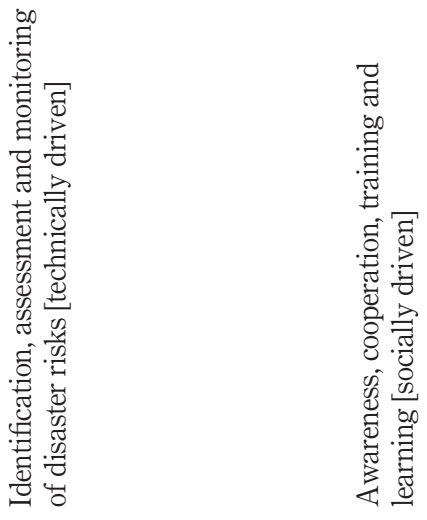

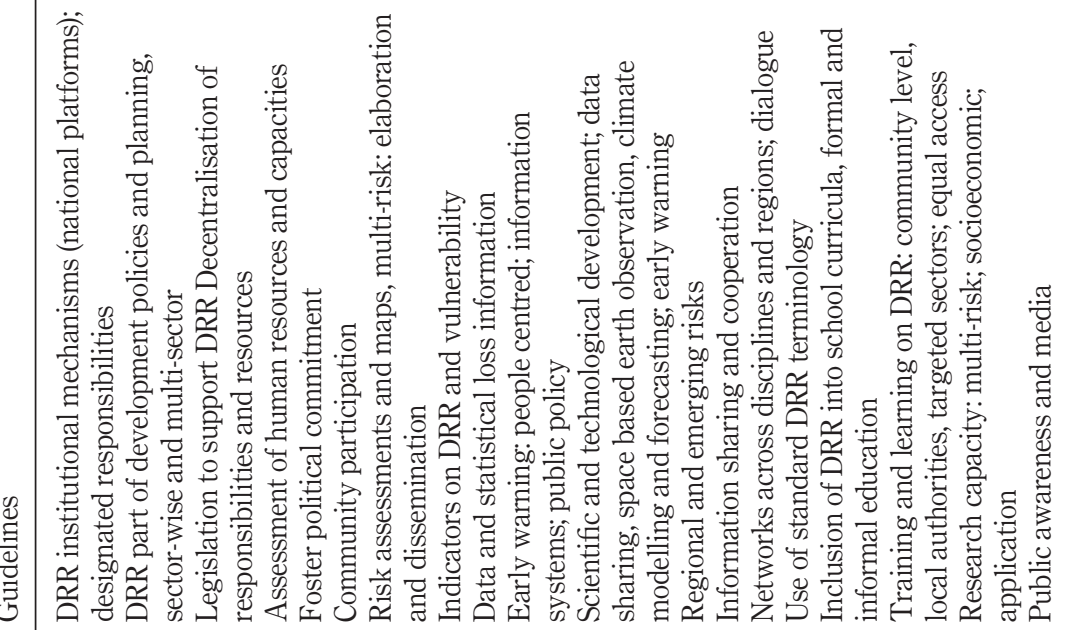
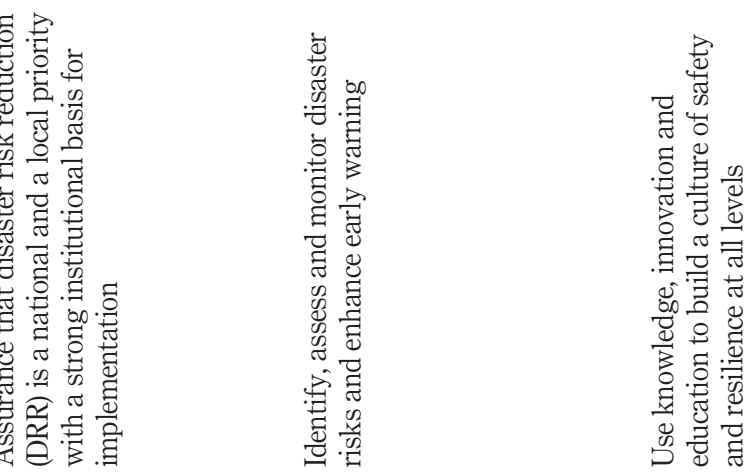


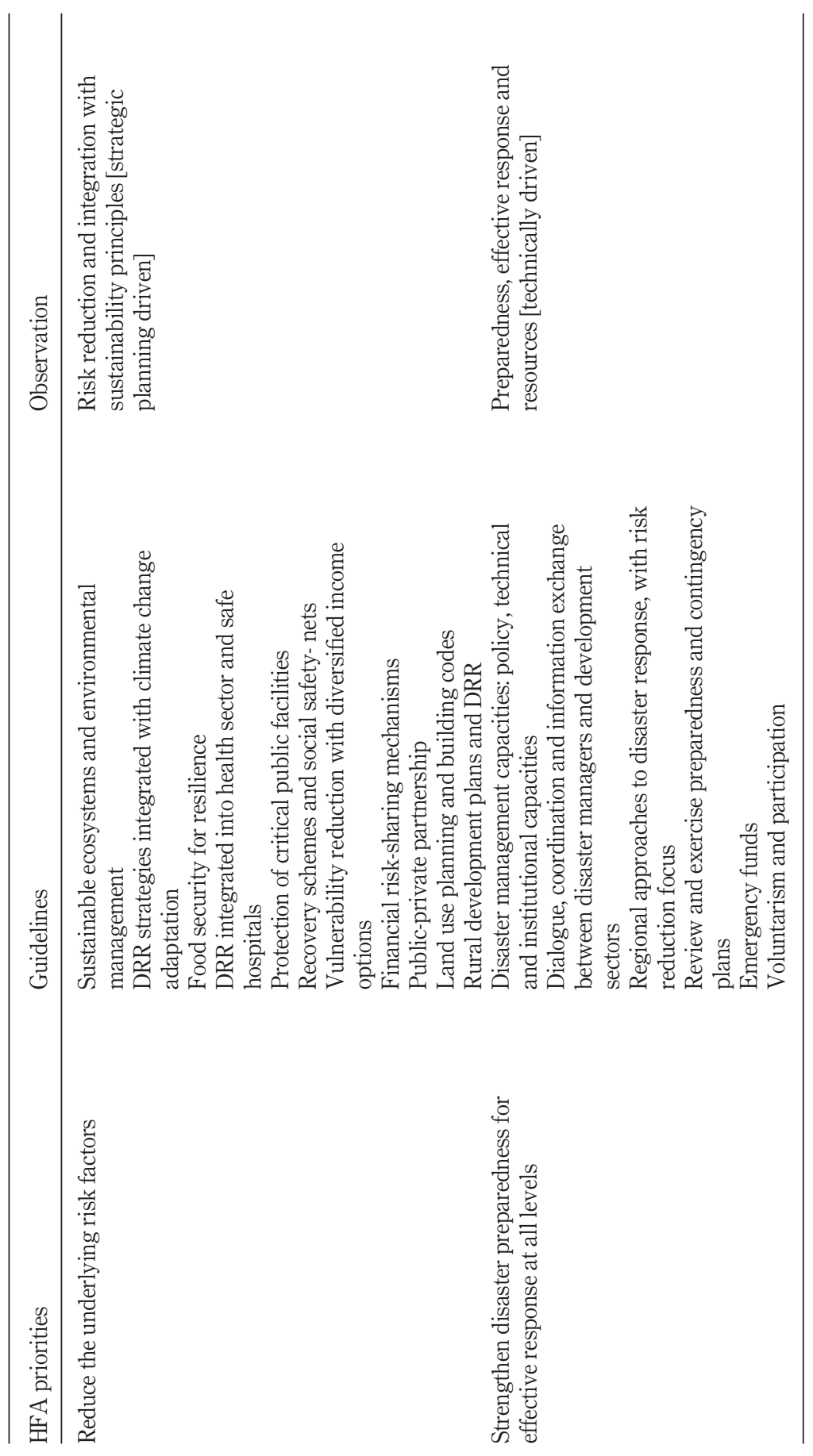

Resilience and sustainability

353

Table I. 


\section{IJDRBE \\ 6,3}

\section{4}

Figure 2.

Resilience and sustainability integration process

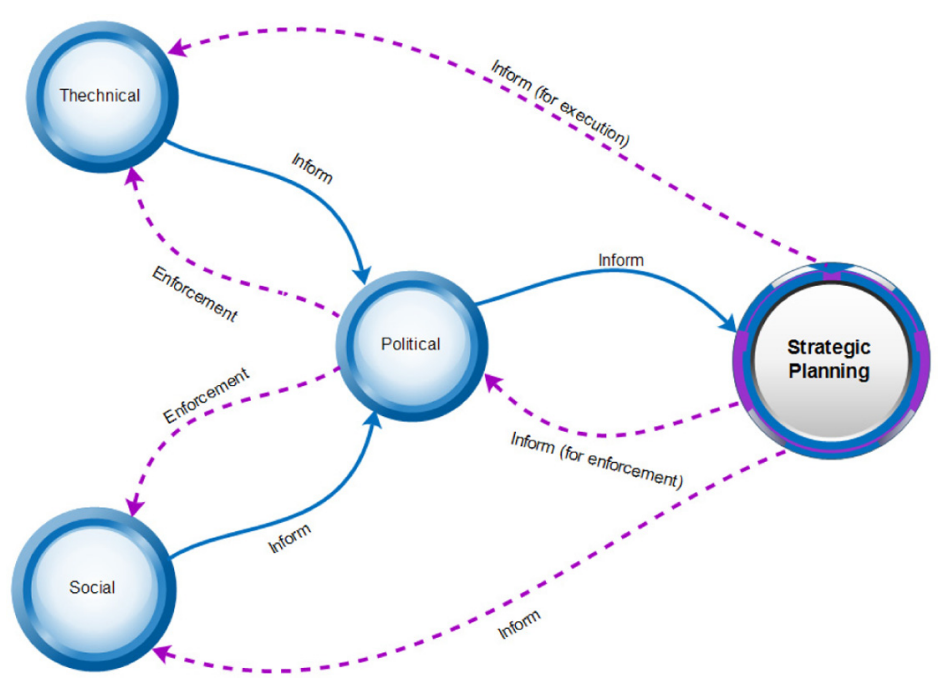

for decision makers. The integration process needs therefore to consider that there are many challenges that need to be carefully addressed, some of which are apparent, but a lot of them are concealed.

\section{Need for culture change and stakeholders' motivation}

There is a common understanding that natural hazards and environmental degradation are linked through global warming and climate change; however, there is lack of evidence that this recognition has turned into action plans and methods to radically change the way resilience and sustainability are addressed. The major challenge is how to change the way these two interdependent issues are addressed?, which is mostly influenced by stakeholder motivation. The literature provides several motivation theories, some of which date back to the early twentieth century, yet they are still relevant and perhaps interesting to adapt in conducting such a change. Examples of these are those theories developed by: Frederick Winslow Taylor (1856-1917), in which he recommended dividing the task into smaller tasks and providing appropriate trainings and tools and rewarding when task is complete; Elton Mayo (1880-1949), who suggested better communication, greater manager involvement and working in groups or teams; and Frederick Herzberg (1923-2000), who encouraged people to lead on their tasks in a "democratic" way so that they feel ownership of the work to be conducted. These theories have been implemented and tested entirely or partially and have demonstrated that they are capable of achieving an acceptable level of success. Among these applications, Nishida and Hua (2011) reported that they involved stakeholders to design the Tokyo's Cap-and-Trade Program (TMG, 2010), which aims at reducing carbon emission in public, commercial and private buildings and engaging stakeholders in the effectiveness of its design. du Plessis and Cole (2011) argued the fact that buildings are complex and stakeholders have different interests, suggesting to change the ways stakeholders are engaged, with particular emphasis on: 
- cooperation and innovative decision-making processes;

Resilience and

- shifting the directions and attitude of people and providing standards to judge the behaviour of individuals and society; and

- identifying an appropriate combination of policies and incentives.

In summary, stakeholder motivation is driven by several issues, such as stakeholders' individual belief and behaviour, supported by the lack of relevant legislations, tools and sustainability models to support the integration process.

\section{Sustainability appraisal tools}

Many countries have developed tools to assess and rate the compliance of their building infrastructure to sustainability requirements. Ten of these (see Table II) were selected, according to the geographical areas they cover, and reviewed with the purpose to explore their design to suggest ways for improvement and resilience integration. The tools comprise a number of checkpoints arranged under headings that reflect the priorities and vision of each country. For example, BEAM allocates 46 per cent of its checkpoints to assess the indoor environmental quality, and $\mathrm{HQE}^{\mathrm{TM}}$ Etablissement de santé Green star and AQUA process (2010) priorities with several issues, such as acoustic and visual comfort and waste management (see Table III). Where relevant legislations are available, tools pursue the compliance with legislative and administrative measures through particular checkpoints. This pursuing action could be through meeting pre-defined compliance levels, such as in CASEBEE ${ }^{\circledR}$, which requires buildings to at least meet the national Building Standards Law earthquake resistance requirements, and when a building exceeds the requirements by 20 or 50 per cent

\begin{tabular}{|c|c|c|c|}
\hline Name of tool & Code & Country & Source \\
\hline $\begin{array}{l}\text { Haute Qualité Environnementale- } \\
\text { Etablissement de santé }\end{array}$ & $\begin{array}{l}\mathrm{HQE}^{\mathrm{TM}} \\
\text { Etablissement de } \\
\text { santé (FR) }\end{array}$ & France & (Senior and Remy, 2004) \\
\hline $\begin{array}{l}\text { Green Start Healthcare } \\
\text { Building Research Establishment } \\
\text { Environmental Assessment } \\
\text { Method for Non-Domestic } \\
\text { Buildings }\end{array}$ & $\begin{array}{l}\text { Green star (AUS) } \\
\text { BREEAM (UK) }\end{array}$ & $\begin{array}{l}\text { Australia } \\
\text { UK }\end{array}$ & $\begin{array}{l}\text { (GBCA, 2009) } \\
\text { (BREEAM, 2012) }\end{array}$ \\
\hline $\begin{array}{l}\text { Leadership in Energy and } \\
\text { Environmental Design }\end{array}$ & LEED (USA) & USA & $\begin{array}{l}\text { LEED } 2009 \text { for } \\
\text { Healthcare Checklist } \\
\text { and USGBC (2011) }\end{array}$ \\
\hline Green Globes & Green Globes ${ }^{\mathrm{TM}}(\mathrm{CA})$ & Canada & (Green Globes, 2004) \\
\hline Green Mark & Green Mark (SG) & Singapore & (BCA, 2010) \\
\hline $\begin{array}{l}\text { Comprehensive Assessment } \\
\text { System for Building } \\
\text { Environmental Efficiency }\end{array}$ & CASBEE® (JP) & Japan & (IBEC, 2008) \\
\hline $\begin{array}{l}\text { German Sustainable Building } \\
\text { Certificate }\end{array}$ & DGNB (DE) & Germany & (DGNB, 2009) \\
\hline AQUA process & AQUA Process (BR) & Brazil & (AQUA, 2010) \\
\hline $\begin{array}{l}\text { Building Environmental } \\
\text { Assessment Method }\end{array}$ & BEAM (HK) & Hong Kong & $\begin{array}{l}\text { (HK-BEAM Society, } \\
\text { 2004) }\end{array}$ \\
\hline
\end{tabular}

Table II.

International sustainability assessment tools for the built environment 


\section{IJDRBE \\ 6,3}

\begin{tabular}{llclr}
\hline & \multicolumn{1}{c}{ 1st priority } & \multicolumn{2}{c}{ 2nd priority } & Ratio \\
Tool & Criteria & 32 & $\begin{array}{l}\text { Resources and materials } \\
(\%)^{\mathrm{a}}\end{array}$ & Criteria \\
\hline CASBEE ${ }^{\mathrm{O}}$ & Indoor environment & $\begin{array}{l}\text { Durability and } \\
\text { reliability }\end{array}$ \\
LEED & Sustainable sites & 25 & $\begin{array}{l}\text { Indoor environment } \\
\text { quality }\end{array}$ & 19 \\
AQUA & $\begin{array}{l}\text { Choice of integrated products, systems } \\
\text { and construction processes }\end{array}$ & 10 & $\begin{array}{l}\text { Construction site } \\
\text { Water }\end{array}$ & 7
\end{tabular}

\section{6}

Table III.

Tools top (first and second) priorities
Waste use and operation of the building

Care and maintenance

Acoustic comfort

Visual comfort

Sanitary of water

$\mathrm{HQE}^{\mathrm{TM}} \quad$ Products, systems and construction

processes

Activity-related waste

Acoustic comfort

Visual comfort

Green Resources

globes $^{\text {TM }}$

DGNB

BREEAM

Green star

Green mark

BEAM

\author{
Ecological quality \\ Management \\ Indoor environment quality \\ Energy efficiency \\ Indoor environment quality
}

Note: ${ }^{a}$ Ratio is defined as the number of relevant checkpoints divided by the total number of checkpoints

10

Construction site

Water

Maintenance and care

Thermal comfort

Water quality

23 Energy

Indoor environment

$23 \quad$ Health and well-being $\quad 17$

26 Health and well-being 21

28 Material 16

42 Environment protection 23

46 Sites aspects 30

3

30

margin, they receive higher scores. The major advantage of this approach is the use of clear mathematical equations and building measurements that will lead to incentive to reach higher scores based on tangible information. The pursuing action could also be through a generic way where the assessor has the flexibility to allocate scores, such as in BEAM and BREEAM. Generic checkpoints imply less guidance and vagueness on what is "acceptable" and what is "not acceptable", leading to "subjectivity" during the scoring process. For example, in $\mathrm{HQE}^{\mathrm{TM}}$, we read: "Ensure a good acoustic insulation" (Senior and Remy, 2004). This will not necessarily lead to a "good acoustic insulation", as it depends on the assessor's experience, knowledge and expectations.

Table IV illustrates that the number of checkpoint in the tools varies between 31 (Green Mark and Green Globes ${ }^{\mathrm{TM}}$, Green Globes, 2004) and 104 (CASBEE ${ }^{\circledR}$ ). This implies that CASBEE ${ }^{\circledR}$ is more comprehensive than the other tools, although issues such as construction process, management and waste management are not explicitly addressed, as is the case in $\mathrm{HQE}^{\mathrm{TM}}$ and BREEAM. CASBEE ${ }^{\circledR}$ escalates the understanding of sustainability to a higher level by assessing the level of integration of recycled materials into not only non-structural but also structural components of the 


\begin{tabular}{|c|c|c|c|c|c|c|}
\hline & & & & Detail of inte & gration & nce and \\
\hline Tool & checkpoints & Integrated? & Criterion & Risks & Checkpoint & \\
\hline CASBEE $®$ & 104 & Yes & $\begin{array}{l}\text { Quality of } \\
\text { service } \\
\text { (Q2) }\end{array}$ & $\begin{array}{l}\text { Earthquakes } \\
\text { Strong wind } \\
\text { Other natural } \\
\text { hazards } \\
\text { Major accidents }\end{array}$ & $\begin{array}{l}\text { Earthquake Resistance } \\
\text { Service of life of } \\
\text { Components } \\
\text { Reliability } \\
\text { Floor Load Margin }\end{array}$ & 357 \\
\hline DGNB $^{\mathrm{a}}$ & 47 & Yes & $\begin{array}{l}\text { Location } \\
\text { quality }\end{array}$ & $\begin{array}{l}\text { Earthquakes } \\
\text { Avalanches } \\
\text { Storms } \\
\text { Manmade } \\
\text { hazards }\end{array}$ & $\begin{array}{l}\text { Risks at the } \\
\text { Microlocation }\end{array}$ & \\
\hline AQUA process & 42 & No & & & & \\
\hline BEAM & 61 & & & & & \\
\hline $\mathrm{HQE}^{\mathrm{TM}}$ & 41 & & & & & \\
\hline Green star & 68 & & & & & \\
\hline BREEAM & 57 & & & & & \\
\hline LEED & 72 & & & & & \\
\hline Green globes & 31 & & & & & \\
\hline Green mark & 31 & & & & & $\begin{array}{l}\text { Table IV. } \\
\text { Tool checkpoints and }\end{array}$ \\
\hline Note: ${ }^{\mathrm{a}}$ This is & optional crit & rrion that does & not influen & the overall sustain & ability compliance rating & resilience integration \\
\hline
\end{tabular}

building. Considering that Japan is a natural hazard-prone country and has strict design requirements, the integration of recycled materials in structural and non-structural components becomes a major challenge that would require managerial processes to be scored against this checkpoint and meet relevant legislative requirements.

Most of the tools do not recognise the link between sustainability and resilience, as they focused on assessing environmental and social impacts through checkpoints such as energy consumption, waste management and comfort. BREEAM and BEAM, however, broadened their focus to include safety issues as part of their "health and wellbeing" and "indoor environmental quality" criteria, which could be seen as a positive indicator towards resilience-sustainability integration and could be broadened further by looking more into resilience to natural hazards. The German Sustainable Building Council (DGNB) and CASBEE ${ }^{\circledR}$ perceptions, however, are much wider, as resilience is well-integrated, as illustrated in Table IV. Although the DGNB approach assesses the quality of the building location with regards to its exposure to earthquakes, avalanches, storms and manmade hazards through a single generic checkpoint (DGNB, 2009), CASBEE ${ }^{\circledR}$ addresses resilience more comprehensively in several locations and through several techniques. The approach is to assess the quality of service during extreme events such as earthquakes, strong winds, and major accidents following checkpoints such as compliance with earthquake resistance code (Checkpoint Q2/2.1), service life of components (Checkpoint Q2/2.2), reliability (Checkpoint Q2/2.4) and floor load margin (Checkpoint Q2/3.2) (IBEC, 2008). Both DGNB and CASBEE ${ }^{\circledR}$ assess the impact of the building on external infrastructure such as connection to public services (DGNB, Checkpoint 61), "sewage load suppression", "traffic load control" and "waste 
IJDRBE

6,3

treatment loads" (CASBEE ${ }^{\circledR}$, Checkpoints LR3/2.3). However, it has to be recognised that DGNB resilience checkpoints are optional and not part of the overall rating.

The amount of detail and the way checkpoints are set out demonstrate the methodological approach and complex development process CASBEE ${ }^{\circledR}$ went through to capture a comprehensive view of sustainability that addresses the improvement of "quality" and "energy", under which the 104 checkpoints fall. Resilience has been introduced within the tool as improvement of "service quality" but then extended to involve impact on the "external infrastructure" and assurance that even structural and non-structural component material must have a proportion of recycled material. There is evidence of major input from a multidisciplinary team of experts with technical and management backgrounds in several fields (technical, social, political and strategic) and consequently led to clarity and tangible targets. Other tools could be improved further by interacting more with the technical side of the process, shown in Figure 2, to include more details to improve the clarity and measurability of each checkpoint specifically considering the fact that some of them have already included some resilience checkpoints (e.g. safety in BEAM and BREEAM).

\section{Conclusions}

There have recently been many disruptive events which re-emphasised the need to mitigate risks associated with, and driven by, the changing climate, and improve the resilience of infrastructure to cope with these hazards better. Many countries have developed strategies to mitigate these risks through the development of tools to assess building compliance to sustainability requirements and developed resilience and disaster prevention plans. However, resilience and sustainability are often approached as two separate issues, which led to predominance of sustainability over resilience. The literature reveals many suggestions and recommendations to integrate resilience and sustainability; however, these remained at a theoretical level and were not taken to the application level.

The integration of resilience and sustainability requires a long and thorough process engaging a multidisciplinary stakeholder team representing technical, strategic, social and political parties. These stakeholders often have different interests, which require innovative ways to build cooperation and shift the directions and attitude of individuals towards the same target. A combination of incentives and policies would support this process and help people work towards the integration of resilience and sustainability.

Most of the tools have made significant steps towards preserving the environment and have set up many criteria that should lead to reduction in the built environment-associated emissions, indoor environment quality, management and safety. However, more work is needed to include resilience criteria, and this can be done by taking/adopting the Japanese approach as a model to be further explored and broadening some sections (e.g. safety or health and well-being) to look at resilience aspects or through addition of new sections that look at the safety and reliability of the building and its contents. The Japanese model has been successful in engaging stakeholders in the process of integration, which led to a comprehensive tool where resilience and sustainability are well-integrated. Clarity and provision of measurable criteria help not only the assessor in conducting the assessment but also the building owners to improve their buildings through tangible targets.

This is a first step and exploratory research work to initiate a discussion about the need for integrating resilience and sustainability as a way to ensure resilient and 
sustainable buildings. This research offers two major lessons. The first is that the integration of resilience and sustainability is technically possible; however, the challenge is whether this will be perceived as a priority or not. The second lesson is that engagement theories worked well in some countries, where they led to the development of integrated tools (e.g. Japan and Germany); however, the challenge is how it will be possible to ensure that stakeholders in other countries do work on achieving the same target with no concealed agendas? These challenges need further investigation to understand the context of each of the examined tools to learn lessons that could be sustainability transferred to countries that have not been covered by this study.

\section{References}

Achour, N. (2007), "Estimation of malfunction of a healthcare facility in case of earthquakes", $\mathrm{PhD}$ thesis, Kanazawa University, Kanazawa.

Achour, N. and Price, A.D.F. (2010), "Resilience strategies of healthcare facilities: present and future", International Journal of Disaster Resilience in the Built Environment, Vol. 1 No. 3, pp. 264-276.

AQUA (2010), Referencial Técnico de Certificação, Fundação Vanzolini, Alto da Lapa.

Arnold, C., Lyons, J., Munger, J., Quinn, R.G. and Smith, T.L. (2004), "Design guide for improving school safety in earthquakes, floods and high winds", Risk Management Series, Federal Emergency Management Agency (FEMA), Washington, DC.

ARUP (2011), Understanding the Transport Infrastructure Requirements to Deliver Growth in England's Core Cities, ARUP, Volterra.

BBC (2008), "Flood risk 'won’t stop nuclear”, BBC, available at: http://news.bbc.co.uk/1/hi/uk politics/7519759.stm (accessed 28 September 2012).

BBC (2009), “UK’s infrastructure 'vulnerable”, BBC, available at: http://news.bbc.co.uk/1/hi/811 6013.stm\#map (accessed 25 May 2012).

BCA (2010), BCA Green Mark: Certification Standard for New Buildings, Building and Construction Authority.

BREEAM (2012), BREEAM New Construction (Non-Domestic Buildings), BRE Global, Watford.

DGNB (2009), German Sustainable Building Certificate, German Sustainable Building Council (DGNB), Stuttgart.

du Plessis, C. and Cole, R.J. (2011), "Motivating change: shifting the paradigm”, Building Research \& Information, Vol. 39 No. 5, pp. 436-449.

EEA (2003), Mapping the Impacts of Recent Natural Disasters and Technological Accidents in Europe, European Environment Agency (EEA), Copenhagen.

FHWA (2013), Data Integration Primer: Challenges to Data Integration, US Department of Transportation: Federal Highway Administration (FHWA), available at: www.fhwa.dot. gov/asset/dataintegration/if10019/dip06.cfm (accessed 19 March 2014).

GBCA (2009), Green Star: As Built Guidelines, Green Building Council Australia, Sydney.

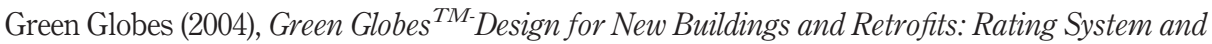
Program Summary, ECD Energy \& Environment Canada, Toronto.

Hancock, B. (2002), An Introduction to Qualitative Research, Trent Focus Group, Nottingham.

Hetzel, R. and Hampel, A. (2006), "Long-term rates of faulting derived from cosmogenic nuclides and short-term variations caused by glacial-interglacial volume changes of 


\section{IJDRBE \\ 6,3}

glaciers and lakes", International Journal of Modern Physics B, Vol. 20 No. 3, pp. 261-276.

HK-BEAM Society (2004), Hong Kong Building Environmental Assessment Method, HK-BEAM Society, Kowloon.

HM Treasury (2013), National Infrastructure Plan 2013, HM Treasury, London.

Höög, E., Garvare, R., Ivarsson, A., Weinehall, L. and Nyström, M.E. (2013), “Challenges in managing a multi-sectoral health promotion program", Leadership in Health Services, Vol. 26 No. 4, pp. 368-386.

IBEC (2008), Comprehensive Assessment System for Building Environmental Efficiency (CASBEE) for New Construction - Technical Manual, Institute for Building Environment and Energy Conservation (IBEC), Tokyo.

IIED (2009), Environmental Impact Assessment (EIA), International Institute for Environment and Development (IIED), London.

McGrath, M. (2009), "UK climate targets 'unachievable”, British Broadcast Corporation (BBC), available at: http://news.bbc.co.uk/1/hi/8358077.stm (accessed 18 February 2010).

Matveev, A.V. (2002), "The advantages of employing quantitative and qualitative methods in intercultural research: practical implications from the study of the perceptions of intercultural communication competence by American and Russian managers", Bulletin of Russian Communication Association, Vol. 1, pp. 59-67.

Mileti, D. (1999), Disasters by Design: A Reassessment of Natural Hazards in the United States, The Joseph Henry Press, Washington, DC.

Moe, T.L. (2012), "Aiming for resilience and adaptation in managing environment: an emerging environmental and emergency leadership in the twenty-first century", International Journal of Disaster Resilience in the Built Environment, Vol. 3 No. 1, pp. 42-51.

Nishida, Y. and Hua, Y. (2011), "Motivating stakeholders to deliver change: Tokyo's Cap-and-Trade Program”, Building Research \& Information, Vol. 39 No. 5, pp. 518-533.

Paskal, C. (2009), The Vulnerability of Energy Infrastructure to Environmental Change, Chatham House, London.

Sauber, J. and Ruppert, N. (2008), "Rapid ice mass loss: does it have an influence on earthquake occurrence in southern Alaska?", in Haeussler, P.J., Wesson, R. and Ekstrom, G. (Eds), Active Tectonics and Seismic Potential of Alaska, Geophysical Monograph Series.

Scrase, J.I. and Sheate, W.R. (2002), "Integration and integrated approaches to assessment: what do they mean for the environment?”, Journal of Environmental Policy \& Planning, Vol. 4 No. 4, pp. 275-294.

Senior, G. and Remy, J.-M. (2004), "RE: Qualité environnementale et développement durable dans la construction: les outils normatifs", GT Enterprises et Construction Durable, Utopies, Paris, France, available at: http://constructiondurable.com/docs/AFNOR@GT200704.pdf (accessed 10 December 2014).

TMG (2010), Tokyo Cap-and-Trade Program: Japan's First Mandatory Emissions Trading Scheme, Tokyo Metropolitan Government (TMG), Tokyo.

UN General Assembly (1994), International Decade for Natural Disaster Reduction, United Nations General Assembly, New York, NY, available at: www.un.org/documents/ga/res/4 9/a49r022.htm (accessed 25 February 2009).

USGBC (2011), LEED 2009 for Healthcare, US Green Building Council (USGBC), Washington, DC. 


\section{About the authors}

Dr Nebil Achour, after gaining a BSc in Civil Engineering from the University of Tunis II (Tunisia), worked in private engineering and design firms on designing structures and computer-aided design and trained engineers in several countries. He was granted a Japanese Government Scholarship to further his education in Kanazawa University (Japan) in 2001, where he later gained his MSc, with a focus on the response of hospital lifeline systems following seismic activities, and his $\mathrm{PhD}$ on risk assessment within healthcare facility systems. Following his graduation, he was then employed as a researcher in his graduate University, and then he joined Loughborough University (UK) as a Research Associate, working on the resilience of healthcare facilities to natural hazards, climate change and sustainability as part of the Health and Care Infrastructure and Research Innovation Centre (HaCIRIC), which he coordinated. Dr Achour joined investigation teams in several countries and was invited as a keynote speaker and guest lecturer and published over 40 scientific publications in journals, prestigious conferences and high-quality reports and a Special Issue of the International Journal of Disaster Resilience in the Built Environment (IJDRBE). He also worked closely with several international organisations such as WHO, PAHO and UN, developing the Hospital Safety Index (HSI) and academic programmes. He also coordinated, and led modules as part of, the Construction Project Management Work-based Distance Learning (CPM WBDL) MSc Programme. His interests include not only disaster prevention and management, physical and social resilience of infrastructure and the built environment to natural hazards and interdisciplinary and international research groups, but also the implementation of theories into the real world. Nebil Achour is the corresponding author and can be contacted at: N.Achour@lboro.ac.uk

Arch. Efthimia Pantzartzis is a Healthcare Architect and Consultant; a Research Associate at Loughborough University, at the Health and Care Infrastructure Research and Innovation Centre (HaCIRIC); and a Health and Safety Coordinator at the project preparations and execution phases (D.Lgs. 81/2008). Efthemia worked on Engineering and Physical Sciences Research Council (EPSRC) and Department of Health (DH)-funded projects on healthcare infrastructure value optimization and critical infrastructure risk. She holds a Master of Science in Planning Buildings for Health from the MARU-South Bank University, with a dissertation on how to develop an appraisal system to measure efficiency in masterplanning of healthcare facilities, and a Master Degree in Architecture from the Polytechnic University of Bari, with a thesis on urban development as an aggregation of patios from residential housing to specialised building complexes. She has been working in the public sector in healthcare planning, design and construction management in Italy, mostly on acute and specialised hospital project refurbishments and reorganisation of services, and worked at the European Topic Centre on Spatial Information and Analysis (ETC-TE LUSI) in Barcelona, with a Leonardo da Vinci scholarship, on the European Commission and European Environment Agency (EEA)-funded projects on EU coastal countries adaptation to climate change.

Dr Federica Pascale gained her BSc and MSc in Civil Engineering with focus on the design of built environment and infrastructure. She won a competition to further her doctoral studies, at the Graduate School of Civil Engineering of University of Naples "Federico II" (Italy), funded by the Local Health Service "ASL Napoli 1". She worked as consultant in private and design firms on healthcare facilities project. Currently, she is a Research Associate in Loughborough University (UK) as part of the Health and Care Infrastructure and Research Innovation Centre (HaCIRIC). Her research focus has been on improving the design of hospital buildings, specifically Accident and Emergency departments (A\&E), with regards to several criteria such as flow, process and capacity to mass casualty events. She has been developing new design strategies and features to improve the flexibility and the capacity of healthcare facilities. 
IJDRBE

6,3

362

Professor Andrew D.F. Price has over 30 years of design, construction and industry-focused research experience. He obtained his BSc degree in Civil Engineering from Nottingham Trent University. He worked for four years as a Structural Engineer for Jackson Peplow Consultants before joining Loughborough University as a Research Assistant in 1981. He became a lecturer in Construction Management in 1984. His early research focussed on construction productivity and the motivation and development of human resources. This evolved to include several project management-related topics, including integrated design and construction, integrated supply chains, partnering and less adversarial long-term relationships. In recent years, his focus has moved towards measuring and improving the socio-economic aspects of construction performance, this has included: construction value, sustainability, performance improvement, total quality management and benchmarking. His current research includes innovative design and construction solutions for health and care infrastructure, continuous improvement and sustainable urban environments. He has graduated $50+\mathrm{PhD} / \mathrm{EngDoc}$ students from 25 countries and acted as an External Examiner at 12 universities as well as a Visiting Professor at four overseas universities. Andrew has published 6 books and over 300 papers in refereed journals and conferences.

For instructions on how to order reprints of this article, please visit our website: www.emeraldgrouppublishing.com/licensing/reprints.htm Or contact us for further details: permissions@emeraldinsight.com 